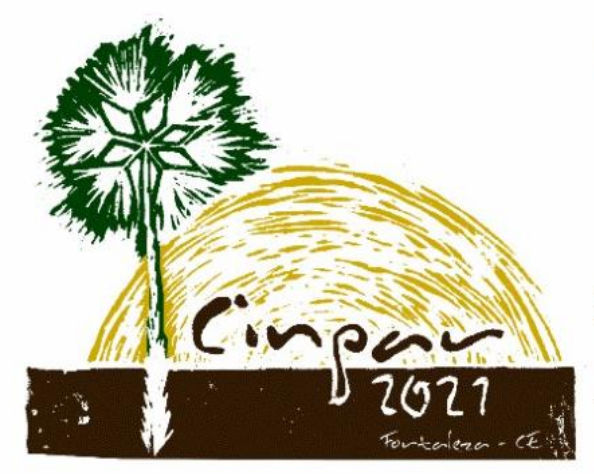

XVII Congresso Internacional sobre Patologia e Reabilitação das Construções

XVII Congreso Internacional sobre Patología y Rehabilitación de las Construcciones

XVII International Conference on Pathology and Constructions Rehabilitation

FORTALEZA (Brasil), 3 a 5 de junho de 2021 https://doi.org/10.4322/CINPAR.2021.031

\title{
Análise das correlações entre a ductilidade com o grau de corrosão e os menores diâmetros de armaduras corroídas naturalmente
}

\section{Analysis of the correlations between ductility with corrosion degree and smaller diameters of naturally corroded reinforcement}

\author{
Thiago A. REICHERT ${ }^{1}$, Carlos E. T. BALESTRA ${ }^{2}$, Gustavo SAVARIS ${ }^{3}$, Lucas B. IBRAHIM ${ }^{4}$, \\ Rodnny J. M. FAKKYE ${ }^{5}$, Wagner A. PANSERA ${ }^{6}$ \\ ${ }^{1}$ Universidade Tecnológica Federal do Paraná, Toledo, Brasil, thiago.reichert@outlook.com \\ ${ }^{2}$ Universidade Tecnológica Federal do Paraná, Toledo, Brasil, carlosbalestra@utfpr.edu.br \\ ${ }^{3}$ Universidade Tecnológica Federal do Paraná, Toledo, Brasil, gsavaris@utfpr.edu.br \\ ${ }^{4}$ Universidade Tecnológica Federal do Paraná, Toledo, Brasil, ibrahim@utfpr.edu.br \\ ${ }^{5}$ Universidade Tecnológica Federal do Paraná, Toledo, Brasil, rodnny@utfpr.edu.br \\ ${ }^{6}$ Universidade Tecnológica Federal do Paraná, Toledo, Brasil, pansera@utfpr.edu.br
}

Resumo: A corrosão das armaduras está entre as principais manifestações patológicas verificadas em estruturas de concreto armado, pois ela leva a uma redução das propriedades mecânicas das barras, principalmente no que tange sua ductilidade. Nesse contexto, correlações podem ser determinadas entre as propriedades mecânicas e a variação de massa das barras (expressa pelo grau de corrosão). Entretanto, quando profundos pontos de corrosão localizada (pites) são verificados nas barras, a variação de massa pode ser pequena frente aos danos causados pela corrosão à seção transversal das armaduras, sendo capaz de trazer dificuldades na interpretação dos resultados, não representando o real estado de degradação mecânica apresentado pela barra corroída. Desse modo, o presente trabalho apresenta uma análise sobre a correlação existente entre a ductilidade das armaduras, corroídas naturalmente e submetidas à tração, tanto com o grau de corrosão quanto com a medida dos menores diâmetros. Para isso, foram analisadas armaduras de espera de blocos de fundação, que pertenceram ao antigo conjunto de fundações da Ala Zero do Instituto Tecnológico de Aeronáutica (ITA), construídos na década de 50 e que permaneceram enterradas por 60 anos devido à paralização das obras na época. Dessas armaduras foram coletados corpos de prova que foram submetidos a processos de decapagem química, de determinação do grau de corrosão e dos menores diâmetros e, posteriormente, a ensaios de tração. Os resultados demonstraram correlação fraca a moderada entre a ductilidade e o grau de corrosão das armaduras, ao passo que foi obtida uma correlação moderada a forte entre a ductilidade e os menores diâmetros das barras, indicando que, de fato, as análises através do grau de corrosão têm dificuldades em expressar os reais efeitos de degradação sobre as propriedades mecânicas das armaduras corroídas.

Palavras-chave: Ensaio de tração, Ductilidade, Corrosão das Armaduras, Estruturas de concreto.

Abstract: Reinforcement corrosion is among the main pathological manifestations observed in reinforced concrete structures, leading to a reduction in the mechanical properties of the bars, especially concerning their ductility. In this context, correlations can be determined between the mechanical properties and the mass variation of the bars (expressed by the corrosion degree). However, when deep localized corrosion points (pits) are verified in the bars, the mass variation can be small in face of the damages caused by corrosion to the reinforcement cross-section, being able to bring difficulties in the interpretation of the results, not representing the real state of mechanical degradation presented by the corroded bar. In this way, 
this work presents an analysis of the correlation between the ductility of the reinforcements, naturally corroded and subjected to tension, both with the corrosion degree and with the measurement of the smallest bar diameters. For this, were analyzed start rebars of foundation blocks, which belonged to the old set of foundations of the Zero Wing of the Technological Institute of Aeronautics (ITA), built in the 50s and which remained buried for 60 years due to the work stoppage in the time. From these reinforcements, specimens were collected and subjected to chemical cleaning processes, determination of the corrosion degree and the smallest diameters, and, subsequently, tensile tests. The results showed a weak to a moderate correlation between the ductility and corrosion degree of the reinforcements, whereas a moderate to a strong correlation between the ductility and the smaller diameters of the bars was obtained, indicating that, in fact, the analysis through the corrosion degree has difficulties in expressing the real degradation effects on the mechanical properties of corroded reinforcement.

Keywords: Tension test, Ductility, Reinforcement corrosion, Concrete structures.

\section{Introdução}

$\mathrm{O}$ pH alcalino da solução presente nos poros do concreto protege as armaduras frente à corrosão, todavia, essa ainda é uma das principais manifestações patológicas observadas em estruturas de concreto armado. 0 processo de corrosão leva à remoção do material metálico das barras e, consequentemente, variações em suas seções transversais, promovendo uma redução progressiva de suas propriedades mecânicas, tais como a resistência ao escoamento, limite de resistência e alongamento final, à medida que o processo corrosivo avança (FRANÇOIS et al., 2013; MEHTA; MONTEIRO, 2006).

Além da redução nas propriedades mecânicas, a corrosão das armaduras gera produtos de corrosão expansivos que, conforme vão se formando, afetam o monolitismo entre o concreto e a armadura, prejudicando, assim, a transferência de esforços entre esses materiais. Por fim, esses produtos de corrosão acabam sendo responsáveis pelo aparecimento de fissuras e destacamento da camada de cobrimento, o que potencializa o ingresso de agentes agressivos do meio ambiente para participar do processo corrosivo (ALMUSALLAM, 2001; HAN et al., 2014).

Nesse contexto, Balestra et al. (2016) demonstraram que, mesmo gerando pequenas variações de massa, a corrosão das armaduras pode produzir significativas reduções nas propriedades mecânicas de armaduras corroídas naturalmente, afetando principalmente a ductilidade das barras. De fato, o estudo de Zhu e François (2014) já havia demonstrado que a corrosão produz excentricidades entre seções das armaduras, de modo que, quanto maiores essas excentricidades, menores são suas resistências. Apostolopoulos et al. (2013) e Imperatore et al. (2017) também corroboram sobre a redução das propriedades mecânicas à medida que a corrosão das barras se intensifica, ressaltando que a capacidade de suportar deformações dessas barras é uma das propriedades mais afetadas pela corrosão.

Mediante o exposto, embora seja consensual que os efeitos da corrosão afetam as propriedades mecânicas das armaduras, muitas das análises são conduzidas em laboratório sob condições controladas e aceleradas, relacionando as propriedades mecânicas das barras corroídas ao seu grau de corrosão (determinado através da variação de massa das barras). Entretanto, considerando que a corrosão por pites profundos (pontos de corrosão definidos na superfície das armaduras, causados pela ação de cloretos, que se aprofundam à medida que o processo corrosivo se intensifica) pode levar a pequenas varrições de massa, porém com significativas reduções na seção das barras, as correlações através do grau de corrosão podem não representar de maneira autêntica o comportamento das barras corroídas (BALESTRA et al., 2016).

Dessa maneira, o presente trabalho apresenta a análise de barras corroídas naturalmente por 50 anos submetidas à ensaios de tração, correlacionando o alongamento final com grau de corrosão das barras e com as medidas de menor diâmetro obtidas ao longo do comprimento dos corpos de prova corroídos, visando elucidar as melhores formas de correlacionar esses dados para evitar interpretações equivocadas a respeito do real dano causado pela corrosão às propriedades das armaduras corroídas.

Análise das correlações entre a ductilidade com o grau de corrosão e menores diâmetros de armaduras ... 


\section{Breve descrição do local de coleta das barras}

As barras utilizadas neste estudo pertenceram ao antigo grupo de fundações da Ala Zero do Instituto Tecnológico de Aeronáutica - ITA (Figura 1). Esse grupo de fundações, composto por estacas, blocos e armaduras de espera, foi executado na década de 50 durante a construção das edificações do instituto, entretanto, as obras foram paralisadas à época, estando executado apenas o grupo de fundação. Dessa maneira, as armaduras de espera foram dobradas e permaneceram enterradas até a data de retomada das obras em 2010, ocasião em que o grupo de fundações foi avaliado para a continuidade das obras. Todavia, devido à problemas de concretagem dos blocos, essas fundações não foram consideradas na retomada das obras, sendo executadas novas fundações.

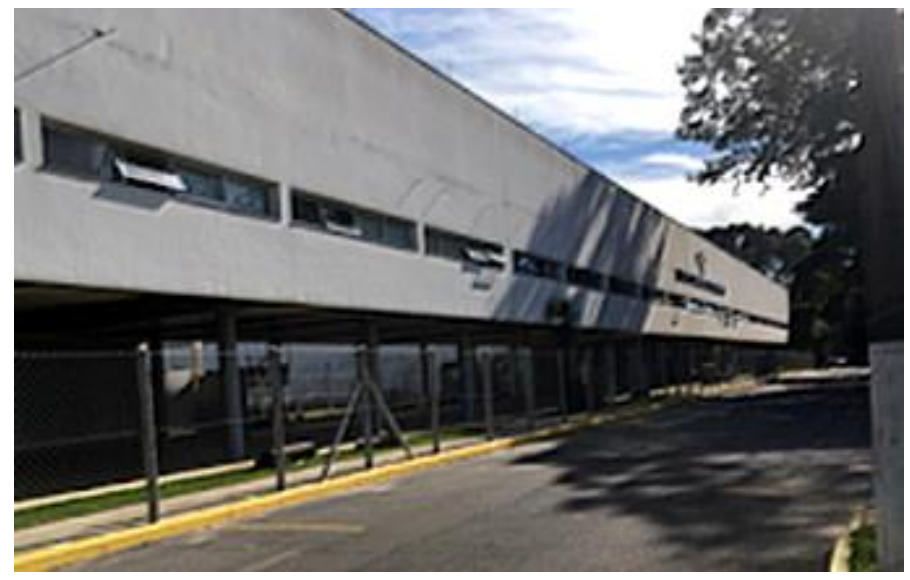

Figura 1 - Vista do edifício da Ala Zero do Instituto Tecnológico de Aeronáutica

\section{Materiais e Métodos}

No ano de 2010, as armaduras de espera, compostas por 20 barras com diâmetro de $15.88 \mathrm{~mm}$, foram cortadas da parte superior dos blocos de fundação para análises de corrosão. Além disso, 5 barras de referência (isentas de corrosão) foram extraídas de um bloco de fundação removido durante as escavações. Nesse ponto, os trechos retilíneos das armaduras foram cortados para a obtenção de corpos de prova, conforme as diretrizes da ABNT NBR 7480 (ASSOCIAÇÃO BRASILEIRA DE NORMAS TÉCNICAS, 2007). Após o corte, os corpos de prova foram submetidos ao processo de decapagem química, para a remoção de produtos de corrosão, utilizando uma solução de hexametilenotetramina, conforme preconiza a norma ASTM G1 (AMERICAN SOCIETY FOR TESTING AND MATERIALS, 2003), sendo realizados ciclos de decapagem até que a massa das barras não apresentasse variações significativas entre medidas sucessivas. A Figura 2 apresenta o aspecto das barras após o procedimento de decapagem química.

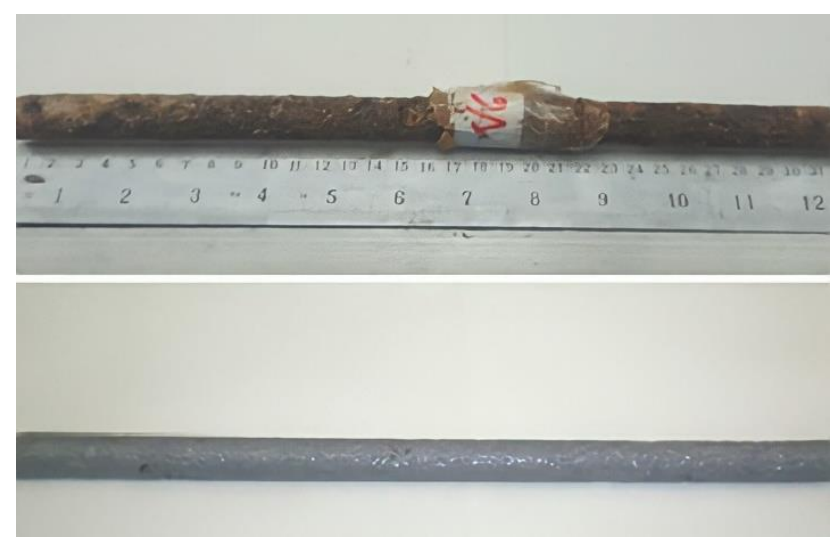

Figura 2 - Barra antes e após processo de decapagem química

Análise das correlações entre a ductilidade com o grau de corrosão e menores diâmetros de armaduras ... 
Após o procedimento de decapagem, o grau de corrosão das barras foi calculado, considerando a massa específica do aço como sendo igual a $7.85 \mathrm{~g} / \mathrm{cm}^{3}$ e o diâmetro original das barras previsto em projeto, permitindo, assim, calcular o grau de corrosão de cada corpo de prova. Após, utilizando um micrômetro dotado de ponteiras cônicas, foram realizadas mais de 30 medidas ao longo do comprimento dos corpos de prova (Figura 3), permitindo assim identificar a menor seção transversal desses. A identificação dos corpos de prova, seu grau de corrosão e menor diâmetro são apresentados na Tabela 1 em conjunto com os dados de alongamento final. Posteriormente, os corpos de prova foram ensaiados à tração, conforme a norma ABNT NBR 6892 (ASSOCIAÇÃO BRASILEIRA DE NORMAS TÉCNICAS, 2002), onde o alongamento final deles foi determinado utilizando um paquímetro.

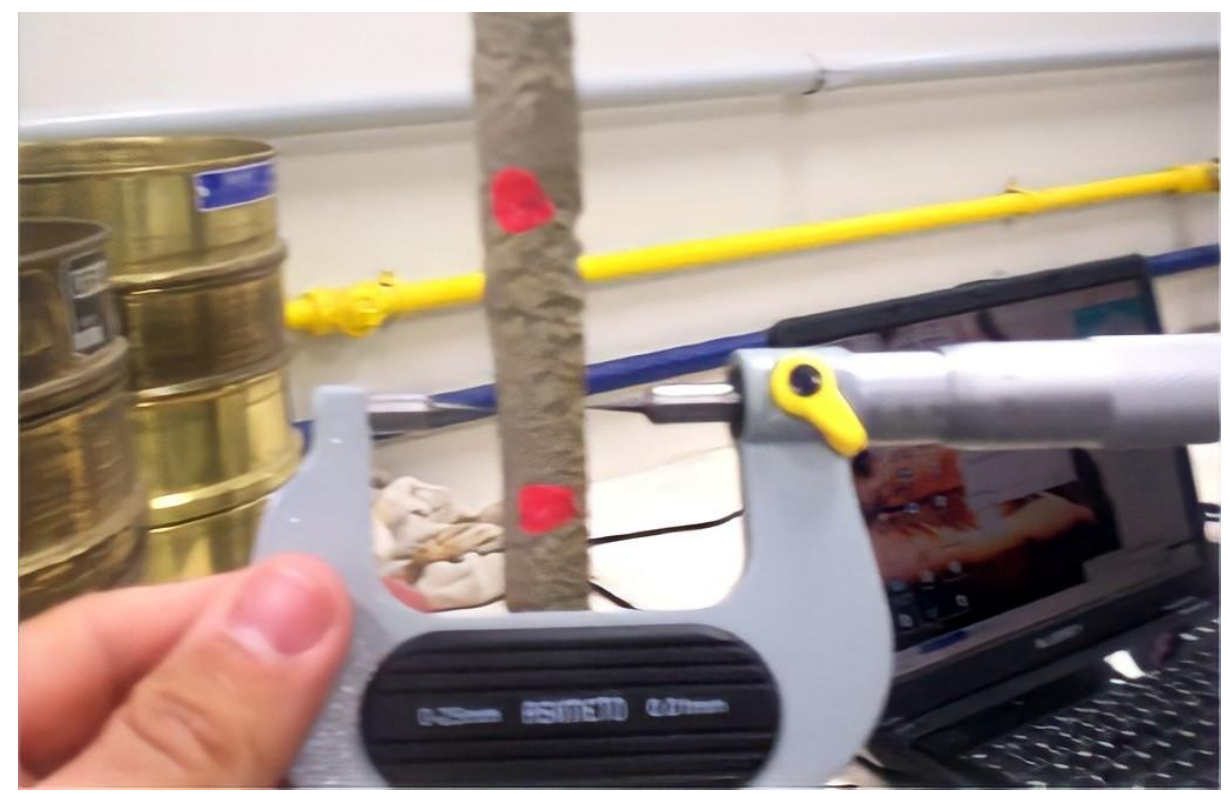

Figura 3 - Exemplo de determinação do menor diâmetro de corpos de prova utilizando um micrômetro

Apostolopoulos e Papadakis (2008) utilizaram o modelo de Weibull (Equação 1) para o ajuste do alongamento final $\epsilon$ (em \%) em função do tempo de exposição (em dias) à corrosão (sendo $a, b$ e $c$ constantes de ajuste do modelo). Nesse ponto, considerando que o grau de corrosão $(G C)$ é proporcional ao tempo de exposição à corrosão, pode-se ajustar o modelo de Weibull conforme apresentado na Equação 2, sendo essa a expressão utilizada, neste trabalho, para correlacionar o grau de corrosão com o alongamento final.

$$
\begin{gathered}
\epsilon(\%)=c \cdot\left[1-\exp \left(-a \cdot t^{-b}\right)\right] \\
\epsilon(\%)=c \cdot\left[1-\exp \left(-a \cdot G C(\%)^{-b}\right)\right]
\end{gathered}
$$

Como o grau de corrosão é proporcional à variação de massa, podemos afirmar que ele é inversamente proporcional à área da seção transversal das barras e, consequentemente, inversamente proporcional ao quadrado do diâmetro $\left(D^{2}\right)$. Com isso, a Equação 2 pode ser reescrita, na forma da Equação 3, de modo a ajustar o modelo de Weibull em relação ao menor diâmetro das barras, sendo essa, portanto, a metodologia utilizada para correlacionar o alongamento final ao menor diâmetro de cada corpo de prova.

$$
\epsilon(\%)=c \cdot\left[1-\exp \left(-a \cdot D^{b}\right)\right]
$$

Portanto, as Equações 2 e 3 fornecem dois modelos para ajuste de dados de alongamento final. Nesse sentido, conforme proposto por Devore (2006), uma análise estatística através do cálculo do erro médio (EM), erro médio absoluto (EMA), raiz do erro quadrático médio (REQM), r-Pearson e intervalo de confiança do r-Pearson foi realizada para as correlações propostas, de modo a identificar o melhor modelo.

Análise das correlações entre a ductilidade com o grau de corrosão e menores diâmetros de armaduras ... 


\section{Resultados e discussão}

A Tabela 1 apresenta, além do grau de corrosão e dos menores diâmetros, os resultados de alongamento final obtidos após o ensaio de tração para cada corpo de prova, obtidos a partir das armaduras corroídas (armaduras de espera). Enquanto isso, a Tabela 2 apresenta os mesmos parâmetros para as barras de referência (armaduras do bloco de fundação).

Tabela 1 - Identificação, grau de corrosão, menor diâmetro e alongamento final dos corpos de prova de armaduras corroídas

\begin{tabular}{cccc}
\hline $\begin{array}{c}\text { Identificação do } \\
\text { corpo de prova }\end{array}$ & $\begin{array}{c}\text { Grau de corrosão } \\
\mathbf{( \% )}\end{array}$ & $\begin{array}{c}\text { Menor diâmetro } \\
(\mathbf{m m})\end{array}$ & $\begin{array}{c}\text { Alongamento final } \\
\mathbf{( \% )}\end{array}$ \\
\hline 1 & 4.22 & 13.45 & 22.13 \\
2 & 1.53 & 14.60 & 22.77 \\
3 & 9.16 & 13.14 & 17.33 \\
4 & 4.86 & 13.18 & 18.03 \\
5 & 7.09 & 13.89 & 25.62 \\
6 & 6.63 & 11.73 & 15.89 \\
7 & 7.14 & 13.18 & 18.48 \\
8 & 5.94 & 13.24 & 17.63 \\
9 & 4.51 & 13.47 & 14.82 \\
10 & 9.90 & 11.89 & 14.03 \\
11 & 13.20 & 13.14 & 19.23 \\
12 & 7.08 & 13.25 & 14.36 \\
13 & 12.56 & 12.93 & 16.61 \\
14 & 4.25 & 13.70 & 23.59 \\
15 & 11.63 & 12.83 & 14.76 \\
16 & 13.20 & 12.90 & 16.63 \\
17 & 4.56 & 14.55 & 19.56 \\
18 & 12.90 & 11.30 & 6.77 \\
19 & 24.15 & 12.15 & 21.56 \\
20 & 24.33 & 10.15 & 12.80 \\
\hline
\end{tabular}

Tabela 2 - Identificação, grau de corrosão, menor diâmetro e alongamento final dos corpos de prova de armaduras de referência

\begin{tabular}{cccc}
\hline $\begin{array}{c}\text { Identificação do } \\
\text { corpo de prova }\end{array}$ & $\begin{array}{c}\text { Grau de corrosão } \\
\mathbf{( \% )}\end{array}$ & $\begin{array}{c}\text { Menor diâmetro } \\
(\mathbf{m m})\end{array}$ & $\begin{array}{c}\text { Alongamento final } \\
\text { (\%) }\end{array}$ \\
\hline R1 & 6.07 & 14.30 & 18.49 \\
R2 & 5.21 & 15.00 & 29.99 \\
R3 & 3.22 & 15.09 & 31.21 \\
R4 & 3.46 & 15.01 & 29.68 \\
R5 & 7.49 & 14.50 & 29.73 \\
\hline
\end{tabular}

Nesse sentido, os dados das Tabelas 1 e 2 fornecem parâmetros para investigar os efeitos do grau de corrosão e dos menores diâmetros sobre o alongamento final das barras de aço. Em geral, observa-se, para a faixa de valores analisada, que os corpos de prova, para um mesmo valor de menor diâmetro, apresentam um aumento de alongamento final proporcional ao aumento do grau de corrosão. Por exemplo, o corpo de prova 3 apresentou menores valores de grau de corrosão e de alongamento final do que o 11, ambos possuindo praticamente o mesmo valor de menor diâmetro. Entretanto, para um mesmo grau de corrosão, verifica-se que uma diminuição do menor diâmetro gera uma diminuição do alongamento final proporcional 
ao quadrado da variação do menor diâmetro. Por exemplo, o corpo de prova 18 apresenta valores de menor diâmetro e de alongamento final menores que o 13, para graus de corrosão semelhantes.

Além disso, é possível afirmar que, mesmo para corpos de prova que apresentem graus de corrosão semelhantes, os efeitos da corrosão nas propriedades mecânicas podem ser distintos entre eles. Sendo assim, a análise a partir do grau de corrosão apresenta dificuldades em expressar o real decréscimo das propriedades mecânicas de barras corroídas, uma vez que o grau de corrosão é determinado a partir da variação de massa dos corpos de prova e não considera a geometria das seções corroídas das barras.

Por outro lado, com base nos dados das Tabelas 1 e 2 e nos modelos das Equações 2 e 3, foram obtidas as Figuras 4 e 5 que apresentam, respectivamente, a correlação do alongamento final com o grau de corrosão e com os menores diâmetros das barras corroídas e de referência. Analisando as Figuras 4 e 5 é possível notar que, à medida que o grau de corrosão aumenta (ou o diâmetro das barras é reduzido), menor foi o alongamento final obtido pelas armaduras. Nesse ponto, observa-se que, de maneira geral, as armaduras de referência, que permaneceram protegidas pelo concreto do bloco de fundação, apresentaram maiores valores de alongamento final.

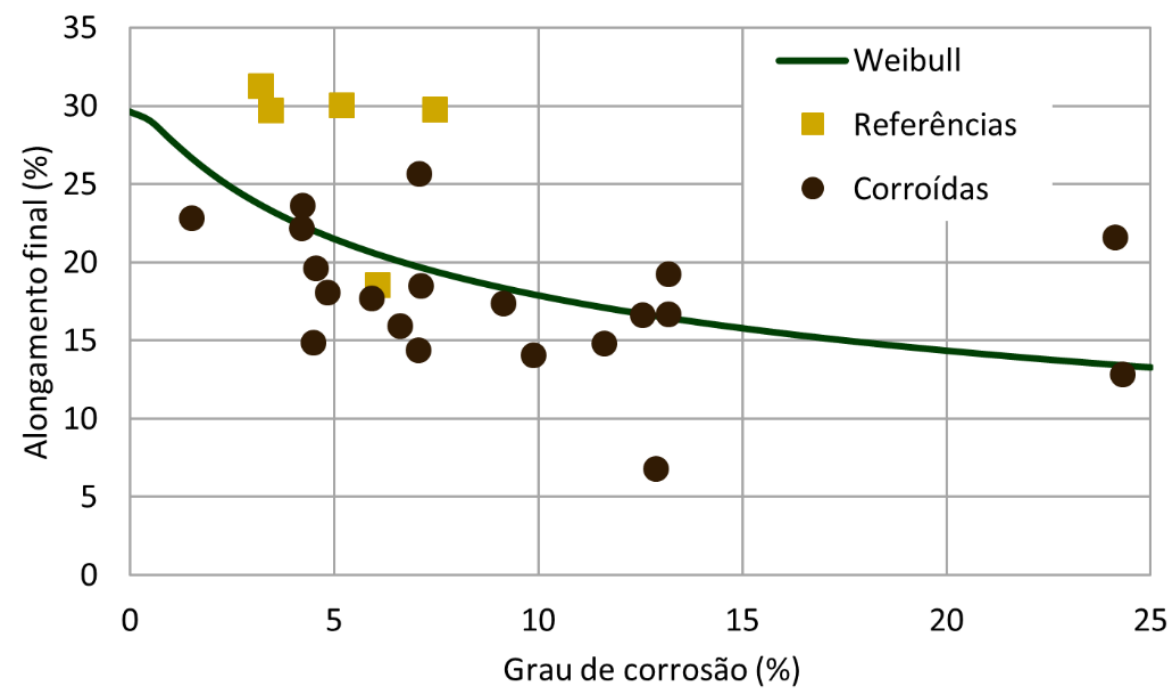

Figura 4 - Correlação entre o alongamento final e o grau de corrosão

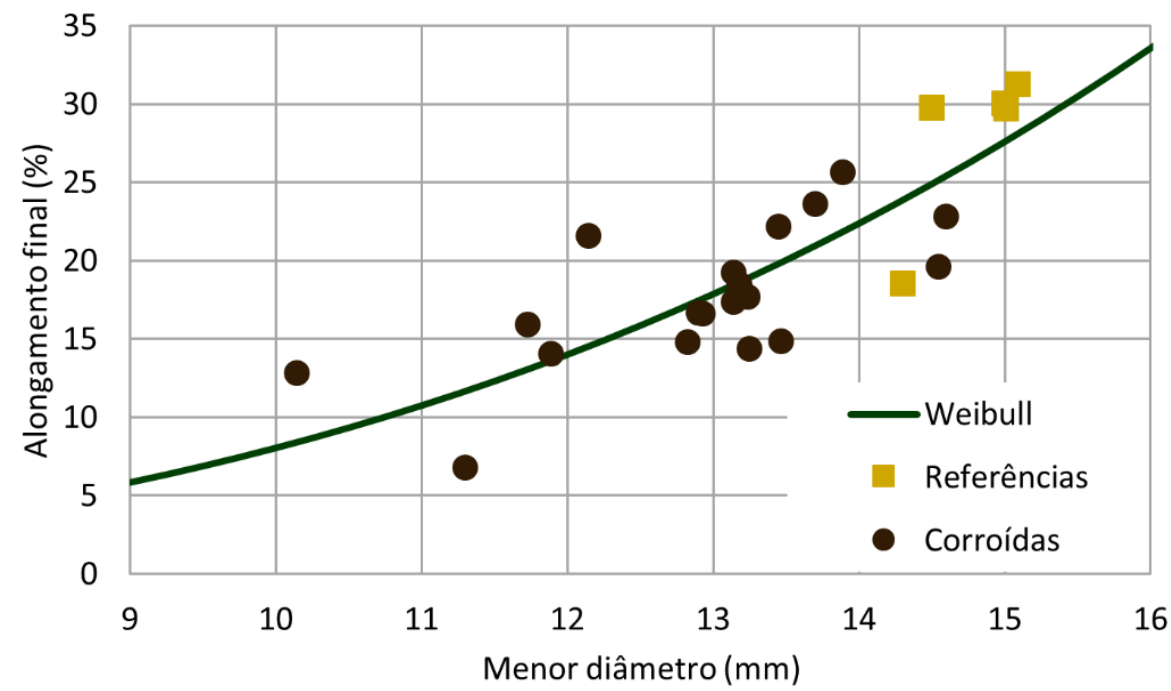

Figura 5 - Correlação entre o alongamento final e os menores diâmetros

Além disso, nota-se que o modelo dado pela Equação de Weibull foi capaz de representar a variação no alongamento final, independentemente se as correlações são realizadas através do grau de corrosão ou dos

Análise das correlações entre a ductilidade com o grau de corrosão e menores diâmetros de armaduras ... 
menores diâmetros. Diante disso, é necessário definir métricas para comparar os ajustes do alongamento final pelo modelo de Weibull utilizando o grau de corrosão e o menor diâmetro. Assim, os dados pertinentes às análises estatísticas desses ajustes são apresentados na Tabela 3.

Tabela 3 - Parâmetros das análises estatísticas

\begin{tabular}{|c|c|c|c|c|c|c|c|c|}
\hline \multirow{2}{*}{ Parâmetro } & \multicolumn{3}{|c|}{$\begin{array}{c}\text { Constantes da Equação de } \\
\text { Weibull }\end{array}$} & \multirow{2}{*}{ EM (\%) } & \multirow{2}{*}{$\begin{array}{c}\text { EMA } \\
(\%)\end{array}$} & \multirow{2}{*}{$\begin{array}{c}\text { REQM } \\
(\%)\end{array}$} & \multirow{2}{*}{ r-Pearson } & \multirow{2}{*}{$\begin{array}{l}\text { Intervalo de } \\
\text { confiança do r- } \\
\text { Pearson (95\%) }\end{array}$} \\
\hline & $\mathbf{a}$ & b & c & & & & & \\
\hline $\begin{array}{l}\text { Grau de } \\
\text { corrosão }\end{array}$ & 2.814 & 0.483 & 29.65 & 8.22 & 23.50 & 36.34 & 0.507 & $(0.140,0.752)$ \\
\hline $\begin{array}{l}\text { Menor } \\
\text { diâmetro }\end{array}$ & $2.54 \cdot 10^{\wedge}(-6)$ & 3.055 & 2782.89 & 3.29 & 16.85 & 22.90 & 0.816 & $(0.621,0.916)$ \\
\hline
\end{tabular}

Observa-se, com base nos resultados, que a dispersão de dados é maior quando o grau de corrosão das armaduras é analisado, em relação ao ajuste realizado com os menores diâmetros. Nesse aspecto, nota-se que mesmo barras com variação de massa da ordem de $5 \%$ podem apresentar alongamento final de $15 \%$ a $30 \%$. Tal fato está relacionado aos danos produzidos pela corrosão à seção transversal das armaduras. Nesse caso, pites profundos, porém de pequeno diâmetro, podem levar a pequenas variações de massa, mas com danos significativos à seção transversal das armaduras.

De fato, as análises estatísticas, apresentadas na Tabela 3, corroboram para essa afirmativa, uma vez que os erros obtidos para o ajuste do alongamento final pelo grau de corrosão são maiores que para o ajuste com os menores diâmetros. Ademais, o coeficiente r-Pearson demonstra o grau de correlação entre os dados observados e os dados ajustados pelos modelos. Nesse sentido, embora um valor do coeficiente r-Pearson superior a 0.50 indique uma correlação moderada, o intervalo de confiança do parâmetro demonstrou que é esperada correlação de fraca a moderada para o ajuste pelo grau de corrosão. Por outro lado, um valor de r-Pearson superior a 0.80 indica correlação forte, assim, no intervalo de confiança de $95 \%$ espera-se correlação de moderada a forte para o ajuste pelos menores diâmetros.

Em outras palavras, a análise pelo grau de corrosão exprime uma correlação mais fraca pois o efeito do menor diâmetro sobre o alongamento final é muito mais significativo. Conforme indicam os dados experimentais das Tabelas 1 e 2, corpos de prova com o mesmo grau de corrosão podem exibir uma grande variação do alongamento final em função da diferença entre os valores dos menores diâmetros. Portanto, as análises estatísticas comprovam que o melhor ajuste para os dados de alongamento final é obtido por meio do modelo de Weibull em função do menor diâmetro dos corpos de prova.

\section{Conclusões}

O presente trabalho analisou a correlação existente entre o alongamento final de armaduras corroídas e de referência com o grau de corrosão e os menores diâmetros. As principais conclusões obtidas são:

- As barras de referência (que permaneceram protegidas pelo concreto) apresentaram valores de alongamento final superiores em relação às barras corroídas, devido ao baixo grau de corrosão dessas barras e aos maiores valores de menor diâmetro. Nesse ponto, a medida que a corrosão por pites se intensifica, levando a uma redução pontual do diâmetro das armaduras, menor é o alongamento final obtido;

- Com base nos menores diâmetros, verifica-se que mesmo pequenas variações de massa podem levar a reduções significativas no alongamento final, devido aos danos produzidos pela corrosão às seções das armaduras; 
- O modelo de Weibull é capaz de correlacionar a redução no alongamento final das barras, independentemente se as análises são conduzidas através do grau de corrosão ou dos menores diâmetros;

- As análises estatísticas mostraram que o ajuste pelo grau de corrosão apresenta uma correlação fraca a moderada, ao passo que o ajuste pelos menores diâmetros exibe correlação moderada a forte. Assim, o modelo de Weibull baseado nos menores diâmetros destacou-se por apresentar o ajuste mais eficiente para os dados de alongamento final.

\section{Agradecimentos}

Os autores agradecem ao Instituto Tecnológico de Aeronáutica e à Universidade Tecnológica Federal do Paraná - Câmpus Toledo.

\section{Referências Bibliográficas}

Almusallam, A.A. (2001). Effect of degree of corrosion on the properties of reinforcing steel bars. Constr. Build. Mater., 15, 361-368. DOI 10.1016/S0950-0618(01)00009-5.

American Society for Testing and Materials (2003). ASTM G1: Standard Practice for Preparing, Cleaning, and Evaluating Corrosion Test. Pennsylvania, United States of America, 2003.

Apostolopoulos, C.A., Demis, S., Papadakis, V.G. (2013). Chloride-induced corrosion of steel reinforcement mechanical performance and pit depth analysis. Constr. Build. Mater., 38, 139-146. DOI 10.1016/ j.conbuildmat.2012.07.087.

Apostolopoulos, C.A., Papadakis, V.G. (2008). Consequences of steel corrosion on the ductility properties of reinforcement bar. Constr. Build. Mater., 22 (12), 2316-2324. DOI 10.1016/j.conbuildmat.2007.10.006.

Associação Brasileira de Normas Técnicas (2002). ABNT NBR 6892: Materiais Metálicos - Ensaio de Tração à Temperatura Ambiente. Rio de Janeiro, Brasil, 2002.

Associação Brasileira de Normas Técnicas (2007). ABNT NBR 7480: Aço destinado a armaduras para estruturas de concreto armado - Especificação. Rio de Janeiro, Brasil, 2007.

Balestra, C.E.T., Lima, M.G., Medeiros-Junior, R.A. (2016). Corrosion degree effect on nominal and effective strengths of reinforcement naturally corroded. J. Mater. Civ. Eng., 28, 04016103. DOI 10.1061/ (ASCE)MT.1943-5533.0001599.

Devore, J.L. (2006). Probabilidade e estatística para engenharia e ciências. Cengage Learning, São Paulo, 2006. 6 ed. ISBN 978-85-221-0924-1.

François, R., Khan, I., Dang, V.H. (2013). Impact of corrosion on mechanical properties of steel embedded in 27-year-old corroded reinforced concrete beams. Mater. Struct., 46, 889-910. DOI 10.1617/s11527-0129941-z.

Han, S.-J., Lee, D.H., Kim, K.S., Seo, S.-Y., Moon, J., Monteiro, P.J.M. (2014). Degradation of flexural strength in reinforced concrete members caused by steel corrosion. Constr. Build. Mater., 54, 572-583. DOI 10.1016/j.conbuildmat.2013.12.101.

Imperatore, S., Rinaldi, Z., Drago, C. (2017). Degradation relationships for the mechanical properties of corroded steel rebars. Constr. Build. Mater., 148, 219-230. DOI 10.1016/j.conbuildmat.2017.04.209.

Mehta, P.K., Monteiro, P.J.M. (2006). Concrete: Microstructure, properties and Materials. Mc-Graw Hill, New York, 2006. 3 ed.

Zhu, W., François, R. (2014). Experimental investigation of the relationships between residual cross-section shapes and the ductility of corroded bars. Constr. Build. Mater., 69, 335-345. DOI 10.1016/j.conbuild mat.2014.07.059. 